\title{
El acompañamiento educativo a nivel de aula: Modelo innovador que permite elevar la Calidad Educativa
}

\author{
Jorge Adelino Pérez Ucelo \\ Licenciado en Pedagogía y Administración Educativa, Maestro en Liderazgo en \\ el Acompañamiento Educativo \\ Dirección Departamental de Educación de Jalapa, Ministerio de Educación de Guatemala \\ jperezucelo.23@gmail.com \\ Vilma Edith Téllez Lima \\ Licenciada en Pedagogía y Administración Educativa, Maestra en Liderazgo en el \\ Acompañamiento Educativo \\ Dirección Departamental de Educación de Jalapa, Ministerio de Educación de Guatemala \\ etellez2366@hotmail.com
}

Fecha de recepción: 02/06/2015 Fecha de aceptación: 14/08/2015

\begin{abstract}
Resumen
El acompañamiento pedagógico realizado en 20 escuelas oficiales rurales del nivel primario en dos municipios del Departamento de Jalapa, permite detectar algunos problemas tanto en aspectos técnico-pedagógicos como administrativos y de liderazgo en directores y docentes. Así mismo, implementa acciones de acompañamiento, orientación y dirección para lograr que directores escolares puedan integrar una visión, misión, mapa de valores y un cronograma específico, para el desarrollo de actividades con personal docente y miembros de la comunidad educativa. Esta estrategia de Acompañamiento Educativo fortalece el liderazgo de directores, motivándolos a desarrollar procesos de acompañamiento a los docentes de primer grado, orientándoles sobre la importancia e implementación de metodologías innovadoras del Curriculum Nacional Base, participan en procesos de capacitación y elaboración del Proyecto Educativo Institucional, practican el aprendizaje significativo, promueven la interacción y el desarrollo de actividades lúdicas, desarrollan evaluación formativa y trabajo en equipo con alumnos y participan en comunidades de aprendizaje. Dichas acciones educativas permiten desarrollar ambientes diferentes, entre las cuales están: Aulas con ambientes letrados, rincones de aprendizaje, escritorios organizados en pequeños grupos de trabajo, con disponibilidad de materiales concretos de acuerdo al contexto de la comunidad. Estos espacios constructivos, motivan para realizar el proceso de enseñanza y aprendizaje de manera creativa y participativa en cada centro educativo.
\end{abstract}

\section{Palabras clave}

Acompañamiento Pedagógico, Liderazgo, Orientación, Metodologías innovadoras, Curriculum Nacional Base -CNB-, Aprendizaje Significativo, Participación, Interacción, Actividades Lúdicas, Ambiente letrado, Rincones de Aprendizaje, visión, misión, mapa de valores, comunidades de aprendizaje.

\begin{abstract}
The educational support officers conducted in 20 rural primary schools in two municipalities in the department of Jalapa, to detect some problems in both pedagogical and technical aspects and administrative leadership principals and teachers. It also implements accompanying measures, guidance and direction to ensure that school directors to integrate a vision, mission, values map and a specific timetable for the development of activities with teachers and members of the educational community. This strategy strengthens educational support the leadership of directors, encouraging them to develop processes of support for teachers of first grade, some guidance on the importance and implementation of innovative methodologies of the National Curriculum, participate in training processes and develop the Institutional Educational Project practice meaningful learning, encourage interaction and development of recreational activities, develop formative assessment and teamwork with students and participate in learning communities. These allow you to organize various educational activities, such as environments: classrooms with literate environments, learning corners, desks organized in small working groups, with availability of particular materials according to the context of the community. These spaces allow constructive educational activities to develop active, creative and participatory manner, which strengthen the quality of learning in students of first grade of primary education.
\end{abstract}

\section{Key words}

Educational support, leadership, guidance, innovative methodologies, National Base Curriculum-CNB-, Meaningful Learning, Participation, Interaction, Leisure Activities, lawyer Environment, Learning Corners. 


\section{Introducción}

Para el cumplimiento de los lineamientos recibidos por parte de la EFPEM y Coordinación de Maestrías del Centro Universitario de Sur Oriente, CUNSURORI, de Jalapa, se implementa el Proyecto de Acompañamiento Educativo a nivel de aula en 20 escuelas del Nivel de Educación Primaria del Departamento de Jalapa, durante el 2013, asignadas a dos profesionales responsables de realizar acompañamiento pedagógico a directores y docentes que atienden primer grado de educación primaria.

El objetivo general del proceso de acompañamiento educativo, permite mejorar la calidad educativa. Específicamente el acompañamiento pedagógico a nivel de aula, mejora el liderazgo del director, desarrolla competencias de acompañamiento pedagógico del director y docentes, promueve la aplicación de evaluación formativa y fortalece la organización y funcionamiento de comunidades de aprendizaje.

Las metas trazadas y cumplidas en el primer semestre del 2013, dio como resultado mejorar el liderazgo de directores y docentes, desarrollar competencias de acompañamiento pedagógico, conformar comunidades de aprendizaje con la participación de maestras y maestros de primer grado a nivel municipal y aplicar procesos de evaluación formativa a nivel de aula, en 20 centros educativos del nivel primario.

El Modelo de acompañamiento educativo, resume distintas estrategias, tareas y acciones específicas implementadas durante la práctica profesional realizada durante el estudio de la Maestría de Liderazgo en el Acompañamiento Educativo. Incluye aspectos relevantes, de impacto y de mucha trascendencia en el acompañamiento educativo realizado en las escuelas seleccionadas para este proceso de mejoramiento continuo en las aulas.
El acompañamiento educativo realizado en escuelas del área rural del departamento de Jalapa, específicamente en dos municipios: Mataquescuintla y Jalapa, aporta elementos positivos que pueden ser tomados en cuenta para el desarrollo de acciones de mejoramiento de la calidad educativa, a corto plazo, principalmente en escuelas del nivel primario de Jalapa, dadas las características geográficas, culturales, económicas y sociopolíticas donde se realizó el acompañamiento pedagógico.

El trabajo realizado, permite definir otras estrategias y acciones puntuales, para implementar en otras escuelas el proceso de coaching o entrenamiento educativo como herramienta eficaz y efectiva para desarrollar competencias de liderazgo y acompañamiento en docentes y directores de las escuelas rurales de Jalapa.

\section{Metodología}

\subsection{Proceso para identificar escuelas}

En la Unidad de Planificación Educativa de la Dirección Departamental de Educación de Jalapa se revisaron los indicadores de no promoción de alumnos de primer grado de educación primaria y en la Unidad de Informática la base de datos de 576 centros educativos del nivel primario, reportados con código, nombre y dirección de ubicación de cada centro educativo, con la finalidad de identificar los centros escolares que demuestran bajos índices de calidad educativa.

De las 20 escuelas seleccionadas, fueron tomadas en cuenta 4 escuelas unitarias, 14 multigrado y 2 gradadas. Identificadas las 20 escuelas, se distribuyeron entre 2 estudiantes de la Maestría en Liderazgo para el Acompañamiento Educativo, de tal manera que las escuelas fueran acompañadas en iguales condiciones como se muestra en las tablas 1 y 2 . 


\section{Tabla 1}

Caracterización del personal docente y del alumnado, antes del acompañamiento pedagógico realizado por la Licda. Vilma Edith Téllez Lima

\begin{tabular}{|c|c|c|c|c|c|}
\hline Escuela & Nombre del director & $\begin{array}{l}\text { Docentes por } \\
\text { grado }\end{array}$ & $\begin{array}{l}\text { Grado y sección } \\
\text { atendida }\end{array}$ & $\begin{array}{l}\text { Alumnos } \\
\text { atendidos }\end{array}$ & $\begin{array}{l}\text { Total de alumnos } \\
\text { inscritos }\end{array}$ \\
\hline $\begin{array}{l}\text { EORM Caserío Las } \\
\text { Quebraditas Aldea } \\
\text { Orchoj, Jalapa }\end{array}$ & $\begin{array}{l}\text { Mynor Roberto Sala- } \\
\text { zar Flores }\end{array}$ & $\begin{array}{l}1 \text { Docente } \\
1 \text { Director }\end{array}$ & $\begin{array}{l}1^{\circ} \cdot A \\
2^{\circ} \cdot A \\
3^{\circ} \cdot A \\
4^{\circ} \cdot A \\
5^{\circ} \cdot A \\
6^{\circ} \cdot A\end{array}$ & $\begin{array}{l}10 \\
08 \\
03 \\
10 \\
12 \\
07\end{array}$ & 50 \\
\hline $\begin{array}{l}\text { EORM Caserío El Lazare- } \\
\text { to, Jalapa }\end{array}$ & $\begin{array}{l}\text { Angélica Ortega } \\
\text { Aguirre }\end{array}$ & $\begin{array}{l}1 \text { Docente } \\
1 \text { Docente } \\
1 \text { Directora } \\
1 \text { Docente }\end{array}$ & $\begin{array}{l}1^{\circ} \cdot A \\
2^{\circ} \cdot A \\
4^{\circ} \cdot A \\
3^{\circ} \cdot A \\
5^{\circ} \cdot A \\
6^{\circ} \cdot A\end{array}$ & $\begin{array}{l}50 \\
38 \\
25 \\
28 \\
30 \\
22\end{array}$ & 193 \\
\hline $\begin{array}{l}\text { EORM Aldea Río Blanco } \\
\text { Abajo, Jalapa }\end{array}$ & $\begin{array}{l}\text { Aura Marina Morales } \\
\text { Arreaga }\end{array}$ & 1 Directora & $\begin{array}{l}1^{\circ} \cdot A \\
2^{\circ} \cdot A \\
4^{\circ} \cdot A \\
3^{\circ} \cdot A \\
5^{\circ} \cdot A \\
6^{\circ} \cdot A\end{array}$ & $\begin{array}{l}05 \\
04 \\
07 \\
02 \\
05 \\
03\end{array}$ & 26 \\
\hline $\begin{array}{l}\text { EORM Aldea Los Tablo- } \\
\text { nes, Jalapa }\end{array}$ & $\begin{array}{l}\text { Hernán Amilcar Casta- } \\
\text { ñeda Vaides }\end{array}$ & $\begin{array}{l}1 \text { Director } \\
1 \text { Docente }\end{array}$ & $\begin{array}{l}1^{\circ} \cdot A \\
2^{\circ} \cdot A \\
3^{\circ} \cdot A \\
4^{\circ} \cdot A \\
5^{\circ} \cdot A \\
6^{\circ} \cdot A\end{array}$ & $\begin{array}{l}06 \\
07 \\
05 \\
08 \\
07 \\
04\end{array}$ & 37 \\
\hline $\begin{array}{l}\text { EORM Aldea La Laguna, } \\
\text { Jalapa }\end{array}$ & $\begin{array}{l}\text { Etelvina López Ma- } \\
\text { rroquín }\end{array}$ & $\begin{array}{l}1 \text { Docente } \\
1 \text { Docente } \\
1 \text { Directora } \\
1 \text { Docente } \\
1 \text { Docente }\end{array}$ & $\begin{array}{l}1^{\circ} \cdot A \\
2^{\circ} \cdot A \\
3^{\circ} \cdot A \\
4^{\circ} \cdot A \\
5^{\circ} \cdot A \\
6^{\circ} \cdot A\end{array}$ & $\begin{array}{l}16 \\
18 \\
14 \\
12 \\
12 \\
06\end{array}$ & 78 \\
\hline $\begin{array}{l}\text { EORM Caserío Los Yanes, } \\
\text { Aldea Río Blanco Arriba, } \\
\text { Jalapa }\end{array}$ & $\begin{array}{l}\text { Gladis Maiden Palma } \\
\text { Folgar }\end{array}$ & 1 Directora & $\begin{array}{l}1^{\circ} \cdot A \\
2^{\circ} \cdot A \\
3^{\circ} \cdot A \\
4^{\circ} \cdot A \\
5^{\circ} \cdot A \\
6^{\circ} \cdot A\end{array}$ & $\begin{array}{l}03 \\
03 \\
01 \\
01 \\
02 \\
03\end{array}$ & 13 \\
\hline $\begin{array}{l}\text { EORM Aldea Los Laure- } \\
\text { les, Jalapa }\end{array}$ & $\begin{array}{l}\text { Brenda Maritza Orte- } \\
\text { ga Gómez }\end{array}$ & $\begin{array}{l}1 \text { Docente } \\
1 \text { Docente } \\
1 \text { Docente } \\
1 \text { Docente } \\
1 \text { Docente } \\
1 \text { Docente } \\
1 \text { Docente }\end{array}$ & $\begin{array}{l}1^{\circ} \cdot A \\
1^{\circ} . B \\
2^{\circ} . A \\
3^{\circ} . A \\
4^{\circ} . A \\
5^{\circ} . A \\
6^{\circ} . A\end{array}$ & $\begin{array}{l}27 \\
27 \\
50 \\
31 \\
37 \\
20 \\
31\end{array}$ & 223 \\
\hline $\begin{array}{l}\text { EORM Caserío Sanuyaso, } \\
\text { Mataquescuintla, Jalapa }\end{array}$ & $\begin{array}{l}\text { Alberto José Monte- } \\
\text { rroso Abrego }\end{array}$ & $\begin{array}{l}1 \text { Docente } \\
1 \text { Docente } \\
1 \text { Docente } \\
1 \text { Docente } \\
1 \text { Director }\end{array}$ & $\begin{array}{l}1^{\circ} \cdot A \\
2^{\circ} \cdot A \\
3^{\circ} \cdot A \\
4^{\circ} \cdot A \\
5^{\circ} \cdot A \\
6^{\circ} \cdot A\end{array}$ & $\begin{array}{l}27 \\
16 \\
10 \\
15 \\
14 \\
11\end{array}$ & 93 \\
\hline
\end{tabular}

Continúa... 


\begin{tabular}{|c|c|c|c|c|c|}
\hline Escuela & Nombre del director & $\begin{array}{l}\text { Docentes por } \\
\text { grado }\end{array}$ & $\begin{array}{l}\text { Grado y sección } \\
\text { atendida }\end{array}$ & $\begin{array}{l}\text { Alumnos } \\
\text { atendidos }\end{array}$ & $\begin{array}{l}\text { Total de alumnos } \\
\text { inscritos }\end{array}$ \\
\hline $\begin{array}{l}\text { EORM Caserío El Pajalito, } \\
\text { Mataquescuintla, Jalapa }\end{array}$ & $\begin{array}{l}\text { Gladys Elizabeth Gon- } \\
\text { zález Pérez }\end{array}$ & $\begin{array}{l}1 \text { Docente } \\
1 \text { Docente } \\
1 \text { Docente } \\
1 \text { Directora }\end{array}$ & $\begin{array}{l}1^{\circ} . A \\
2^{\circ} . A \\
3^{\circ} . A \\
5^{\circ} . A \\
6^{\circ} . A \\
4^{\circ} . A\end{array}$ & $\begin{array}{l}23 \\
22 \\
11 \\
08 \\
08 \\
12\end{array}$ & 83 \\
\hline $\begin{array}{l}\text { EORM Caserío Buena Vis- } \\
\text { ta San Granadita, Aldea } \\
\text { San Granada, Mataques- } \\
\text { cuintla, Jalapa }\end{array}$ & $\begin{array}{l}\text { Rolando de Jesús } \\
\text { Lémus Pacheco }\end{array}$ & 1 Director & $\begin{array}{l}1^{\circ} . A \\
2^{\circ} \cdot A \\
3^{\circ} . A \\
4^{\circ} . A \\
5^{\circ} . A\end{array}$ & $\begin{array}{l}08 \\
05 \\
03 \\
03 \\
04\end{array}$ & 23 \\
\hline Totales 10 & 10 & 23 & & & 819 \\
\hline
\end{tabular}

Fuente: Elaboración propia, 2012

Tabla 2

Caracterización del personal docente y del alumnado, antes del acompañamiento pedagógico realizado por el Lic. Jorge Adelino Pérez Ucelo

\begin{tabular}{|c|c|c|c|c|c|}
\hline Escuela & Nombre del director & $\begin{array}{c}\text { Docentes por } \\
\text { grado }\end{array}$ & $\begin{array}{l}\text { Grado y sección } \\
\text { atendida }\end{array}$ & $\begin{array}{l}\text { Alumnos } \\
\text { atendidos }\end{array}$ & $\begin{array}{l}\text { Total de alumnos } \\
\text { inscritos }\end{array}$ \\
\hline $\begin{array}{l}\text { EORM Cas. San } \\
\text { Francisco, Ald. Sansupo, } \\
\text { Mataquescuintla }\end{array}$ & $\begin{array}{l}\text { Arnoldo Enrique Mix } \\
\text { Loy }\end{array}$ & $\begin{array}{l}1 \text { Docente } \\
1 \text { Docente } \\
1 \text { Director }\end{array}$ & $\begin{array}{l}1^{\circ} \cdot A \\
2^{\circ} . A \\
3^{\circ} . A \\
4^{\circ} . A \\
5^{\circ} . A \\
6^{\circ} . A\end{array}$ & $\begin{array}{l}14 \\
09 \\
10 \\
06 \\
10 \\
13\end{array}$ & 62 \\
\hline $\begin{array}{l}\text { EORM Cas. El Porvenir, } \\
\text { Ald. El Escobal, } \\
\text { Mataquescuintla }\end{array}$ & $\begin{array}{l}\text { Mario Leonel Sando- } \\
\text { val Martínez }\end{array}$ & 1 Director & $\begin{array}{l}1^{\circ} \cdot A \\
2^{\circ} \cdot A \\
3^{\circ} \cdot A \\
4^{\circ} \cdot A \\
5^{\circ} \cdot A \\
6^{\circ} \cdot A\end{array}$ & $\begin{array}{l}05 \\
02 \\
01 \\
02 \\
04 \\
03\end{array}$ & 17 \\
\hline $\begin{array}{l}\text { EORM Cas. La } \\
\text { Esperanza, Ald. Sansupo, } \\
\text { Mataquescuintla }\end{array}$ & $\begin{array}{l}\text { Oscar Noé Domín- } \\
\text { guez Hernández }\end{array}$ & $\begin{array}{l}1 \text { Director } \\
1 \text { Docente }\end{array}$ & $\begin{array}{l}1^{\circ} \cdot A \\
2^{\circ} \cdot A \\
3^{\circ} \cdot A \\
4^{\circ} \cdot A \\
5^{\circ} \cdot A \\
6^{\circ} \cdot A\end{array}$ & $\begin{array}{l}19 \\
10 \\
06 \\
00 \\
02 \\
04\end{array}$ & 41 \\
\hline $\begin{array}{l}\text { EORM Cas. Pinalito, Ald. } \\
\text { Hierba Buena, Jalapa }\end{array}$ & $\begin{array}{l}\text { Leyda Roxana Gonzá- } \\
\text { lez Cisneros }\end{array}$ & $\begin{array}{l}1 \text { Docente } \\
1 \text { Docente } \\
1 \text { Docente } \\
1 \text { Docente } \\
1 \text { Directora }\end{array}$ & $\begin{array}{l}1^{\circ} \cdot A \\
2^{\circ} \cdot A \\
3^{\circ} \cdot A \\
4^{\circ} \cdot A \\
5^{\circ} \cdot A \\
6^{\circ} \cdot A\end{array}$ & $\begin{array}{l}42 \\
28 \\
31 \\
30 \\
24 \\
17\end{array}$ & 172 \\
\hline $\begin{array}{l}\text { EORM Cas. Laguna } \\
\text { Del Sapo, Ald. Sashico, } \\
\text { Jalapa }\end{array}$ & $\begin{array}{l}\text { Leslie Mabel Vicente } \\
\text { Rosil }\end{array}$ & $\begin{array}{l}1 \text { Docente } \\
1 \text { Docente } \\
1 \text { Docente } \\
1 \text { Docente } \\
1 \text { Directora }\end{array}$ & $\begin{array}{l}1^{\circ} \cdot A \\
2^{\circ} \cdot A \\
3^{\circ} . A \\
4^{\circ} . A \\
5^{\circ} . A \\
6^{\circ} \cdot A\end{array}$ & $\begin{array}{l}44 \\
31 \\
26 \\
32 \\
25 \\
17\end{array}$ & 175 \\
\hline
\end{tabular}

Continúa... 


\begin{tabular}{|c|c|c|c|c|c|}
\hline Escuela & Nombre del director & $\begin{array}{l}\text { Docentes por } \\
\text { grado }\end{array}$ & $\begin{array}{l}\text { Grado y sección } \\
\text { atendida }\end{array}$ & $\begin{array}{l}\text { Alumnos } \\
\text { atendidos }\end{array}$ & $\begin{array}{l}\text { Total de alumnos } \\
\text { inscritos }\end{array}$ \\
\hline $\begin{array}{l}\text { Eorm Cas. Laguna Seca, } \\
\text { Ald Sashico, Jalapa }\end{array}$ & $\begin{array}{l}\text { Marleen Ericka Solór- } \\
\text { zano Campos }\end{array}$ & $\begin{array}{l}1 \text { Docente } \\
1 \text { Docente } \\
1 \text { Docente } \\
1 \text { Directora }\end{array}$ & $\begin{array}{l}1^{\circ} . \mathrm{A} \\
1^{\circ} \mathrm{B} \\
2^{\circ} . \mathrm{A} \\
3^{\circ} . \mathrm{A} \\
4^{\circ} . \mathrm{A} \\
5^{\circ} . \mathrm{A} \\
6^{\circ} . \mathrm{A}\end{array}$ & $\begin{array}{l}82 \\
31 \\
16 \\
10 \\
18 \\
14\end{array}$ & 171 \\
\hline $\begin{array}{l}\text { EORM Cas. El Quetzal, } \\
\text { Ald. La Fuente, Jalapa }\end{array}$ & $\begin{array}{l}\text { Marleny Elicenia Mo- } \\
\text { rales Zapata }\end{array}$ & $\begin{array}{l}1 \text { Directora } \\
1 \text { Docente } \\
1 \text { Docente }\end{array}$ & $\begin{array}{l}1^{\circ} . A \\
2^{\circ} . A \\
3^{\circ} . A \\
4^{\circ} . A \\
5^{\circ} . A \\
6^{\circ} . A\end{array}$ & $\begin{array}{l}41 \\
27 \\
24 \\
12 \\
11 \\
06\end{array}$ & 121 \\
\hline $\begin{array}{l}\text { EORM Cas. Los Cruces, } \\
\text { Ald. El Durazno, Jalapa }\end{array}$ & $\begin{array}{l}\text { Ribelino Francisco } \\
\text { Ucelo Jiménez }\end{array}$ & $\begin{array}{l}1 \text { Docente } \\
1 \text { Docente } \\
1 \text { Director }\end{array}$ & $\begin{array}{l}1^{\circ} . A \\
2^{\circ} . A \\
3^{\circ} . A \\
4^{\circ} . A \\
5^{\circ} . A \\
6^{\circ} . A\end{array}$ & $\begin{array}{l}20 \\
24 \\
16 \\
14 \\
13 \\
07\end{array}$ & 94 \\
\hline $\begin{array}{l}\text { EORM Cas. El Pino, Ald. } \\
\text { El Durazno, Jalapa }\end{array}$ & $\begin{array}{l}\text { Marisela Marroquín } \\
\text { Cisneros }\end{array}$ & $\begin{array}{l}1 \text { Docente } \\
1 \text { Directora } \\
1 \text { Docente } \\
1 \text { Docente }\end{array}$ & $\begin{array}{l}1^{\circ} . A \\
2^{\circ} . A \\
3^{\circ} . A \\
4^{\circ} . A \\
5^{\circ} . A \\
6^{\circ} . A\end{array}$ & $\begin{array}{l}39 \\
31 \\
32 \\
18 \\
17 \\
22\end{array}$ & 159 \\
\hline $\begin{array}{l}\text { EORM Cas. Laguneta, } \\
\text { Ald. El Durazno, Jalapa }\end{array}$ & $\begin{array}{l}\text { Ana Gladys Cordero } \\
\text { Berdúo }\end{array}$ & $\begin{array}{l}1 \text { Docente } \\
1 \text { Docente } \\
1 \text { Docente } \\
1 \text { Docente } \\
1 \text { Docente } \\
1 \text { Docente } \\
1 \text { Docente } \\
1 \text { Docente } \\
1 \text { Docente } \\
1 \text { Docente } \\
1 \text { Docente } \\
1 \text { Docente } \\
1 \text { Docente } \\
1 \text { Docente } \\
1 \text { Docente }\end{array}$ & $\begin{array}{l}1^{\circ} . \mathrm{A} \\
1^{\circ} . \mathrm{B} \\
1^{\circ} \text {. C } \\
2^{\circ} . \mathrm{A} \\
2^{\circ} . \mathrm{B} \\
2^{\circ} \text {. C } \\
3^{\circ} . \mathrm{A} \\
3^{\circ} . \mathrm{B} \\
3^{\circ} \text {. C } \\
4^{\circ} \text {. A } \\
4^{\circ} . \mathrm{B} \\
5^{\circ} . \mathrm{A} \\
5^{\circ} . \mathrm{B} \\
6^{\circ} . \mathrm{A} \\
6^{\circ} . \mathrm{B}\end{array}$ & $\begin{array}{c}100 \\
65 \\
80 \\
90 \\
51 \\
44\end{array}$ & 更 \\
\hline Totales 10 & 10 & 36 & & & 1442 \\
\hline
\end{tabular}

Fuente: Elaboración propia, año 2012. 


\subsection{Técnicas de Investigación aplicadas}
a. Observación
b. Entrevista
c. Conversar, observar, conversar (C.O.C.)
d. Documental
e. Campo

\subsection{Instrumentos utilizados}
a. Formato Entrevista al Director
b. Recolección de Información de Da- tos Básicos del Centro educativo
c. Bitácora para el Acompañamiento Pedagógico
d. Libro para Registrar Visitas de Acompañamiento

\subsection{Equipo utilizado en el acompañamiento educativo}
a. Equipo cómputo
b. Proyector
c. Impresora
d. Cámara digital
e. Motocicleta
f. Vehículo

\section{5 Área geográfica del acompañamiento realizado}

Catorce escuelas del nivel primario área rural en el municipio de Jalapa y 6 escuelas del nivel primario, área rural del municipio de Mataquescuintla.

\subsection{Causas que originaron el acompañamiento pedagógico}

Informe presentado por USAID/Reforma Educativa en el Aula (2010), sobre el fracaso promedio de 83 escuelas oficiales del Programa Nacional de Autogestión Comunitaria -PRONADE- área rural del departamento de Jalapa. Específicamente para este proceso han sido revisados indicadores de fracaso escolar en el nivel primario de las veinte escuelas agrupadas en las tablas 3 y 4 . 
Tabla 3

Registro de Resultados Finales de Promoción, Ciclo Escolar 2012 de escuelas acompañadas por la Licda. Vilma Edith Téllez Lima

\begin{tabular}{|c|c|c|c|c|c|c|c|c|c|}
\hline \multirow[b]{2}{*}{$\begin{array}{l}\text { Código unidad } \\
\text { de informatica }\end{array}$} & \multirow[b]{2}{*}{$\begin{array}{l}\text { Nombre de } \\
\text { la escuela }\end{array}$} & \multirow[b]{2}{*}{$\begin{array}{l}\text { Nombre del } \\
\text { director }\end{array}$} & \multirow[b]{2}{*}{$\begin{array}{l}\text { Docentes } \\
\text { por } \\
\text { grado }\end{array}$} & \multirow[b]{2}{*}{$\begin{array}{l}\text { Grado y } \\
\text { sección } \\
\text { atendida }\end{array}$} & \multicolumn{5}{|c|}{ CICLO ESCOLAR 2012} \\
\hline & & & & & $\begin{array}{l}\text { Total de } \\
\text { alumnos } \\
\text { inscritos }\end{array}$ & $\begin{array}{l}\text { Promo- } \\
\text { vidos }\end{array}$ & $\begin{array}{l}\text { No Pro- } \\
\text { movidos }\end{array}$ & $\begin{array}{l}\text { Retirados } \\
\text { Definitiva- } \\
\text { mente }\end{array}$ & $\begin{array}{l}\text { Retirados } \\
\text { por } \\
\text { Traslado }\end{array}$ \\
\hline 21-01-0028-43 & $\begin{array}{l}\text { EORM } \\
\text { Caserío Las } \\
\text { Quebraditas } \\
\text { Aldea Orchoj, } \\
\text { Jalapa }\end{array}$ & $\begin{array}{l}\text { Mynor } \\
\text { Roberto } \\
\text { Salazar } \\
\text { Flores }\end{array}$ & $\begin{array}{c}1 \\
\text { Docente }\end{array}$ & $1^{\circ} \cdot A$ & 10 & 4 & 6 & 0 & 0 \\
\hline \multirow{2}{*}{$21-01-0031-43$} & \multirow{2}{*}{$\begin{array}{l}\text { EORM Caserío } \\
\text { El Lazareto, } \\
\text { Jalapa }\end{array}$} & \multirow{2}{*}{$\begin{array}{l}\text { Angélica } \\
\text { Ortega } \\
\text { Aguirre }\end{array}$} & $\begin{array}{c}1 \\
\text { Docente }\end{array}$ & $1^{\circ} \cdot A$ & 25 & 16 & 9 & 0 & 0 \\
\hline & & & $\begin{array}{c}1 \\
\text { Docente }\end{array}$ & $1^{\circ} . \mathrm{B}$ & 25 & 13 & 7 & 5 & 0 \\
\hline $21-01-0056-43$ & $\begin{array}{l}\text { EORM Aldea } \\
\text { Río Blanco } \\
\text { Abajo, Jalapa }\end{array}$ & $\begin{array}{l}\text { Aura } \\
\text { Marina } \\
\text { Morales } \\
\text { Arreaga }\end{array}$ & $\begin{array}{l}1 \text { Direc- } \\
\text { tora }\end{array}$ & $1^{\circ} \cdot A$ & 5 & 3 & 2 & 0 & 0 \\
\hline $21-01-0061-43$ & $\begin{array}{l}\text { EORM Aldea } \\
\text { Los Tablones, } \\
\text { Jalapa }\end{array}$ & $\begin{array}{l}\text { Hernán } \\
\text { Amílcar } \\
\text { Castañeda } \\
\text { Vaides }\end{array}$ & 1 Director & $1^{\circ} . \mathrm{A}$ & 6 & 3 & 2 & 0 & 1 \\
\hline $21-01-0079-43$ & $\begin{array}{l}\text { EORM Aldea } \\
\text { La Laguna, } \\
\text { Jalapa }\end{array}$ & $\begin{array}{l}\text { Etelvina } \\
\text { López } \\
\text { Marroquín }\end{array}$ & $\begin{array}{c}1 \\
\text { Docente }\end{array}$ & $1^{\circ} \cdot A$ & 16 & 9 & 5 & 2 & 0 \\
\hline $21-01-0198-43$ & $\begin{array}{l}\text { EORM Caserío } \\
\text { Los Yanes, } \\
\text { Aldea Río } \\
\text { Blanco Arriba, } \\
\text { Jalapa }\end{array}$ & $\begin{array}{l}\text { Gladis } \\
\text { Maiden } \\
\text { Palma } \\
\text { Folgar }\end{array}$ & $\begin{array}{c}1 \\
\text { Directora }\end{array}$ & $1^{\circ} \cdot A$ & 3 & 2 & 1 & 0 & 0 \\
\hline \multirow{2}{*}{$21-01-1242-43$} & \multirow{2}{*}{$\begin{array}{l}\text { EORM Aldea } \\
\text { Los Laureles, } \\
\text { Jalapa }\end{array}$} & \multirow{2}{*}{$\begin{array}{l}\text { Brenda } \\
\text { Maritza } \\
\text { Ortega } \\
\text { Gómez }\end{array}$} & $\begin{array}{c}1 \\
\text { Docente }\end{array}$ & $1^{\circ} \cdot A$ & 30 & 18 & 5 & 4 & 3 \\
\hline & & & $\begin{array}{c}1 \\
\text { Docente }\end{array}$ & $1^{\circ} . \mathrm{B}$ & 24 & 19 & 1 & 4 & 0 \\
\hline $21-07-0048-43$ & $\begin{array}{l}\text { EORM Caserío } \\
\text { Sanuyaso, Ma- } \\
\text { taquescuintla, } \\
\text { Jalapa }\end{array}$ & $\begin{array}{l}\text { Alberto } \\
\text { José } \\
\text { Monterroso } \\
\text { Abrego }\end{array}$ & $\begin{array}{c}1 \\
\text { Docente }\end{array}$ & $1^{\circ} \cdot A$ & 27 & 12 & 11 & 0 & 4 \\
\hline $21-07-0052-43$ & $\begin{array}{l}\text { EORM Caserío } \\
\text { El Pajalito, Ma- } \\
\text { taquescuintla, } \\
\text { Jalapa }\end{array}$ & $\begin{array}{l}\text { Gladys } \\
\text { Elizabeth } \\
\text { González } \\
\text { Pérez }\end{array}$ & $\begin{array}{c}1 \\
\text { Docente }\end{array}$ & $1^{\circ} \cdot A$ & 23 & 15 & 8 & 0 & 0 \\
\hline $21-07-0053-43$ & $\begin{array}{l}\text { EORM Caserío } \\
\text { Buena Vista } \\
\text { San Granadi- } \\
\text { ta, Aldea San } \\
\text { Granada, Ma- } \\
\text { taquescuintla, } \\
\text { Jalapa }\end{array}$ & $\begin{array}{l}\text { Rolando } \\
\text { de Jesús } \\
\text { Lemus } \\
\text { Pacheco }\end{array}$ & 1 Director & $1^{\circ} \cdot A$ & 8 & 5 & 1 & 0 & 2 \\
\hline
\end{tabular}

Fuente: Estadística Final Primer Grado, Ministerio de Educación, año 2012 


\section{Tabla 4}

Registro de Resultados Finales de Promoción, Ciclo Escolar 2012 de escuelas acompañadas por el Lic. Jorge Adelino Pérez Ucelo

\begin{tabular}{|c|c|c|c|c|c|c|c|c|c|}
\hline \multirow[b]{2}{*}{$\begin{array}{l}\text { Código unidad } \\
\text { de informatica }\end{array}$} & \multirow[b]{2}{*}{$\begin{array}{c}\text { Nombre de la } \\
\text { escuela }\end{array}$} & \multirow[b]{2}{*}{$\begin{array}{c}\text { Nombre } \\
\text { del director }\end{array}$} & \multirow[b]{2}{*}{$\begin{array}{c}\text { Docentes } \\
\text { por } \\
\text { grado }\end{array}$} & \multirow[b]{2}{*}{$\begin{array}{l}\text { Grado y } \\
\text { seccion } \\
\text { atendida }\end{array}$} & \multicolumn{5}{|c|}{ CICLO ESCOLAR 2012} \\
\hline & & & & & $\begin{array}{l}\text { Total de } \\
\text { alumnos } \\
\text { inscritos }\end{array}$ & $\begin{array}{l}\text { Promo- } \\
\text { vidos }\end{array}$ & $\begin{array}{l}\text { No Pro- } \\
\text { movidos }\end{array}$ & $\begin{array}{c}\text { Retirados } \\
\text { Definitiva- } \\
\text { mente }\end{array}$ & $\begin{array}{c}\text { Retirados } \\
\text { por Tras- } \\
\text { lado }\end{array}$ \\
\hline $21-07-0032-43$ & $\begin{array}{l}\text { EORM Caserío, } \\
\text { San Francisco, } \\
\text { Mataques- } \\
\text { cuintla }\end{array}$ & $\begin{array}{l}\text { Arnoldo } \\
\text { Enrique } \\
\text { Mix Loy }\end{array}$ & $\begin{array}{c}1 \\
\text { Docente }\end{array}$ & $1^{\circ} \cdot A$ & 14 & 11 & 2 & 1 & 0 \\
\hline $21-07-0034-43$ & $\begin{array}{l}\text { EORM Caserío } \\
\text { El Porvenir, } \\
\text { Mataques- } \\
\text { cuintla }\end{array}$ & $\begin{array}{l}\text { Mario } \\
\text { Leonel } \\
\text { Sandoval } \\
\text { Martínez }\end{array}$ & $\begin{array}{c}1 \\
\text { Director }\end{array}$ & $1^{\circ} \cdot A$ & 5 & 2 & 3 & 0 & 0 \\
\hline $21-07-0051-43$ & $\begin{array}{l}\text { EORM Caserío } \\
\text { La Esperanza, } \\
\text { Mataques- } \\
\text { cuintla }\end{array}$ & $\begin{array}{l}\text { Oscar Noé } \\
\text { Domínguez } \\
\text { Hernández }\end{array}$ & $\begin{array}{c}1 \\
\text { Director }\end{array}$ & $1^{\circ} \cdot A$ & 19 & 8 & 9 & 2 & 0 \\
\hline $21-01-0057-43$ & $\begin{array}{l}\text { EORM Case- } \\
\text { río Laguneta, } \\
\text { Jalapa }\end{array}$ & $\begin{array}{l}\text { Ana Gladys } \\
\text { Cordero } \\
\text { Berdúo }\end{array}$ & $\begin{array}{c}3 \\
\text { Docentes }\end{array}$ & $\begin{array}{l}1^{\circ} \cdot \mathrm{A} \\
1^{\circ} \cdot \mathrm{B} \\
1^{\circ} . \mathrm{C}\end{array}$ & 100 & 56 & 24 & 20 & 0 \\
\hline $21-01-0162-43$ & $\begin{array}{l}\text { EORM Caserío } \\
\text { Laguna del } \\
\text { Sapo, Jalapa }\end{array}$ & $\begin{array}{l}\text { Leslie Ma- } \\
\text { bel Vicente } \\
\text { Rosil }\end{array}$ & $\begin{array}{c}1 \\
\text { Docente }\end{array}$ & $1^{\circ} \cdot A$ & 44 & 27 & 17 & 0 & 0 \\
\hline $21-01-0164-43$ & $\begin{array}{l}\text { EORM Caserío } \\
\text { Laguna Seca, } \\
\text { Jalapa }\end{array}$ & $\begin{array}{l}\text { Marleen } \\
\text { Ericka } \\
\text { Solórzano } \\
\text { Campos }\end{array}$ & $\begin{array}{c}2 \\
\text { Docentes }\end{array}$ & $\begin{array}{l}1^{\circ} \cdot \mathrm{A} \\
1^{\circ} . \mathrm{B}\end{array}$ & 82 & 45 & 37 & 0 & 0 \\
\hline $21-01-0175-43$ & $\begin{array}{l}\text { EORM Caserío } \\
\text { EI Pinalito, } \\
\text { Jalapa }\end{array}$ & $\begin{array}{l}\text { Leyda } \\
\text { Roxana } \\
\text { González } \\
\text { Cisneros }\end{array}$ & $\begin{array}{c}1 \\
\text { Docente }\end{array}$ & $1^{\circ} \cdot A$ & 42 & 31 & 11 & 0 & 0 \\
\hline 21-01-0199-43 & $\begin{array}{l}\text { EORM Caserío } \\
\text { El Quetzal, } \\
\text { Jalapa }\end{array}$ & $\begin{array}{l}\text { Marleny } \\
\text { Elicenia } \\
\text { Morales } \\
\text { Zapata }\end{array}$ & $\begin{array}{c}1 \\
\text { Directora }\end{array}$ & $1^{\circ} \cdot A$ & 41 & 19 & 20 & 2 & 0 \\
\hline $21-01-0202-43$ & $\begin{array}{l}\text { EORM Caserío } \\
\text { El Pino, Jalapa }\end{array}$ & $\begin{array}{l}\text { Marisela } \\
\text { Marroquín } \\
\text { Cisneros }\end{array}$ & $\begin{array}{c}1 \\
\text { Docente }\end{array}$ & $1^{\circ} \cdot A$ & 39 & 19 & 20 & 0 & 0 \\
\hline 21-01-0204-43 & $\begin{array}{l}\text { EORM Caserío } \\
\text { Los Cruces, } \\
\text { Jalapa }\end{array}$ & $\begin{array}{l}\text { Ribelino } \\
\text { Francisco } \\
\text { Ucelo Jimé- } \\
\text { nez }\end{array}$ & $\begin{array}{c}1 \\
\text { Docente }\end{array}$ & $1^{\circ} \cdot \mathrm{A}$ & 20 & 9 & 8 & 3 & 0 \\
\hline
\end{tabular}

Fuente: Estadística Final Primer Grado, Ministerio de Educación, año 2012 


\section{Antecedentes}

\subsection{Breve descripción del Acompañamiento Pedagógico}

Las estrategias implementadas para realizar acompañamiento pedagógico a los centros educativos han revelado que la supervisión educativa desarrolla un papel eminentemente fiscalizador de acciones administrativas, controles, registros y cumplimiento a requerimientos escritos; más que asesorar las acciones técnicas a nivel de aula.

Derivado de este modelo poco prometedor de la supervisión escolar, se han diseñado otras estrategias e implementado acciones que buscan mejorar las funciones de supervisión a los centros educativos. En este sentido, la aplicación de la herramienta del coaching evidencia buenos resultados en regiones del país donde se ha implementado como muestra piloto. Según García, Romero (2001) el acompañamiento educativo a nivel de aula se convierte en un eje facilitador de experiencias educativas recuperadas creativamente y con mayor impacto en el desarrollo personal y profesional.

En el departamento de Jalapa el acompañamiento pedagógico ha tomado importancia por los resultados positivos para el mejoramiento de la calidad educativa en las escuelas seleccionadas para este proceso; estos indicadores de calidad ratifican lo que señala Brigg (2000) "el acompañamiento pedagógico que a diario utiliza el director y cuyo objetivo es orientar a través de procesos técnicos, desarrollar destrezas y mantener la sensibilidad a través de las relaciones humanas".

En este sentido, la función del director irá mucho más lejos de hacer únicamente observaciones de clase, éste deberá apasionarse por su trabajo, empoderarse de la calidad que desea en su escuela, detectar la diferencia entre lo que es hoy en día y el deber ser implícito que refiere Brigg (2000); pues el acompañamiento pedagógico no sólo es necesario para el director, sino para el docente que lo amerite; combinando los procesos y desarrollando en ellos seguridad en lo que hacen, de modo que cultiven la autoestima entre la comunidad educativa de la cual forman parte.

En consecuencia, el modelo de acompañamiento educativo, debe destinarse a todos los centros educativos de los diferentes niveles y sectores, tomando en consideración los resultados positivos de la práctica profesional realizada por los profesionales en las escuelas beneficiadas cuyos indicadores reflejan los niveles superados en cuanto a liderazgo, metodología en el aula, participación en comunidades de aprendizaje y formas diversas de evaluación de los aprendizajes en el aula.

Otros indicadores a tomar en cuenta lo constituyen la deserción escolar, la repitencia y la promoción en primer grado; pues las estadísticas de resultados finales de promoción correspondientes al ciclo escolar 2013, de las 20 escuelas acompañadas, muestran la reducción en la deserción y repitencia y el aumento de estadísticas de promoción. Por tal razón el modelo de acompañamiento educativo a nivel de aula debe constituirse en parte fundamental del trabajo que todo profesional que tiene a cargo procesos de supervisión educativa debe tomar en cuenta para lograr cambios sustanciales de calidad.

\section{Proceso del Acompañamiento Educativo}

\subsection{Acciones de Organización y Planificación}

Para la autorización de reuniones con directores de escuelas donde se realiza el acompañamiento pedagógico, la Dirección Departamental de Educación de Jalapa, autorizó el plan departamental de acompañamiento pedagógico. A raíz de esta acción, fue dirigida solicitud a supervisores que atienden los dife- 
rentes Distritos Educativos del departamento de Jalapa, elaborándose para el efecto, cronograma de visitas preliminares al personal de las escuelas que participaron en el Acompañamiento Pedagógico.

Después de reunir a los directores de los centros educativos seleccionados, para la recopilación de información diagnóstica, fue elaborado un plan personal para el acompañamiento pedagógico dirigido a las escuelas asignadas a cada profesional; dicho plan incluye objetivos, metas y fines, siendo los que se describen a continuación:

\section{Objetivos:}

\section{General:}

Contribuir al mejoramiento de la calidad educativa, mediante el desarrollo del proceso de Acompañamiento Pedagógico a nivel de aula, en escuelas del Nivel de Educación Primaria de los municipios de Mataquescuintla y Jalapa, departamento de Jalapa.

\section{Específicos:}

a) Mejorar el Liderazgo del Director Escolar en los Centros Educativos del Nivel de Educación Primaria de los municipios de Mataquescuintla y Jalapa, departamento de Jalapa.

b) Desarrollar competencias de acompañamiento pedagógico en los Directores Escolares, para apoyar a los docentes a nivel de aula.

c) Formar comunidades de aprendizaje en los centros educativos del nivel primario que forman parte del proyecto de acompañamiento pedagógico en el departamento de Jalapa.

d) Promover la aplicación del proceso de evaluación, utilizando adecuadamente las herramientas de evaluación formativa, en escuelas del departamento de Jalapa.

\section{Metas}

- Mejorar el Liderazgo de los Directores Escolares, en 10 Centros Educativos del Nivel de Educación Primaria de los municipios de Mataquescuintla y Jalapa, departamento de Jalapa, durante el primer semestre del ciclo escolar 2013.

- Desarrollar competencias de acompañamiento pedagógico en 10 Directores Escolares de los municipios de Mataquescuintla y Jalapa, departamento de Jalapa, para apoyar a los docentes a nivel de aula, durante el primer semestre del ciclo escolar 2013.

- Conformar comunidades de aprendizaje en 10 centros educativos del nivel primario, que forman parte del proyecto de acompañamiento pedagógico en los municipios de Mataquescuintla y Jalapa, departamento de Jalapa.

- Diez escuelas apliquen el proceso de evaluación, utilizando adecuadamente las herramientas de evaluación formativa, en los municipios de Mataquescuintla y Jalapa del departamento de Jalapa, durante el primer semestre 2013.

Fines:

a. Lograr la formación integral de niños y niñas de primer grado de educación primaria del departamento de Jalapa, con una educación basada en principios humanos, científicos, técnicos, culturales y espirituales, capaces de resolver problemas cotidianos en el contexto en que se desenvuelven.

b. Formar líderes educativos con conciencia crítica de la realidad jalapaneca en función de su proceso histórico para que asumiéndola participen activa y responsablemente en la búsqueda de soluciones económicas, sociales, políticas y humanas. 


\subsection{Acciones de Ejecución y Reflexión}

El primer paso fue visitar a supervisores educativos para informales acerca de la actividad y obtener la aprobación y autorización, para implementar el proceso de acompañamiento pedagógico en las escuelas correspondientes al distrito que atienden. De mutuo acuerdo fue necesario establecer redes de comunicación constante con autoridades de la USAC, DIDEDUC, supervisores educativos, directores-as y docentes de las escuelas.

Otro paso importante lo constituyó el desarrollo del proceso de mejoramiento continuo a nivel de dirección escolar y a nivel de aula en cada escuela en cinco visitas, una cada mes con la finalidad de revisar la planificación, la metodología y el proceso de evaluación aplicado por cada docente; reorientar acciones en conjunto a través de las visitas de aula, aplicando el mapa de reflexión que consiste en planificar y enseñar, observar en el aula, reflexionar conjuntamente con el docente sobre las debilidades observadas, evaluar, planificar y practicar otras acciones, para el mejoramiento continuo.

Así mismo, la implementación y uso de materiales educativos proporcionados por el Ministerio de Educación, alineados al Curriculum Nacional Base-CNB-, aulas letradas, rincones de aprendizaje, práctica de valores, trabajo en equipo, en pares, individual, colaborativo, enseñanza a través de actividades lúdicas, organización y activación de comunidades de aprendizaje con docentes de primer grado, para la socialización y sistematización de experiencias exitosas practicadas con los alumnos.

En relación al aprendizaje de los alumnos, fue desarrollado mediante la metodología activa participativa, constructiva, formativa, interactiva, elaboración y utilización de herramientas didácticas tales como caja lógica, lotería, adivinanzas, sopa de letras, caja de arena, ábacos, ristras, pared de palabras, abanicos, dados, ruletas, libritos de cuentos, poemas, acrósticos, tendederos, aulas creativas ambientadas para el desarrollo y práctica de la lectura, elaboración de teatrinos, títeres, material didáctico elaborado con la utilización de recursos disponibles en la comunidad. A través de este proceso de aprendizaje, se dio cumplimiento a los pasos del aprendizaje significativo.

\subsection{Acciones de Evaluación y Seguimiento}

La elaboración de libro de visitas, bitácora, boleta del director y boleta del centro educativo, para registrar y controlar avance de las actividades del director y actividades del docente en el aula. Posteriormente, se utiliza el proceso de sistematización de experiencias pedagógicas durante el proceso de acompañamiento educativo, así quedó evidenciado el cumplimiento de las estrategias y propuestas de solución por medio de los resultados siguientes:

- Directores de centros educativos cuentan con visión, misión, mapa de valores y cronograma de actividades con miembros de la comunidad educativa.

- $\quad$ Directores desarrollan procesos de acompañamiento a los docentes de primer grado, orientándoles sobre la importancia de la implementación de metodologías innovadoras y el Curriculum Nacional Base.

- Maestros practicando aprendizaje significativo, promoviendo la interacción y trabajo en equipo de sus alumnos.

- Maestros con ambiente letrado en su aula, rincones de aprendizaje enriquecidos, haciendo uso de materiales concretos de acuerdo al contexto de la comunidad.

El acompañamiento educativo a nivel de aula, realizado por el profesional asignado a cada escuela, marcó el inicio de una nueva etapa en el trabajo a nivel de dirección escolar, puesto que quedaron sentadas las bases so- 
bre las cuales deberá orientarse el trabajo de acompañamiento del director hacia el docente; esto implica que cada escuela gozará de autonomía en el desarrollo de las actividades inherentes al proceso de cambio, atendiendo las posibilidades de cada contexto, tomando como referente el modelaje de acompañamiento realizado.

Por otro lado, el proceso de transformación iniciado en las escuelas acompañadas, exige la participación directa de quienes tienen a cargo funciones de supervisión educativa, en el sentido de realizar acompañamiento y seguimiento con la finalidad de que este modelo de acompañamiento sea sostenible y sustentable.

\section{Fundamento Teórico}

\subsection{Educación}

En términos generales y de acuerdo a lo establecido en la Constitución Política de la República de Guatemala (1985) la educación tiene como fin primordial el desarrollo integral de la persona humana, el conocimiento de la realidad y cultura nacional y universal, (...). Se declara de interés nacional la educación, la instrucción, formación social y la enseñanza sistemática de la Constitución Política de la República y de los Derechos Humanos (Art. 72).

El proceso educativo podría decirse entonces que tiene como finalidad el desarrollo integral de la persona humana, que comprende cambios no solo intelectuales, sino emocionales, sociales y el desarrollo de habilidades.

Cabe destacar en esta perspectiva, que los seres humanos dentro de una sociedad adquieren continuamente conocimientos a lo largo de toda la vida. Es así como las personas se superan como seres humanos dentro de una sociedad en la que debe respetarse su dignidad, tanto dentro como fuera del sistema escolar.

\subsection{Importancia de la Educación}

Algunos autores relacionados a esta problemática, coinciden en que la educación debe reflejarse en sus finalidades y sus contenidos; abriendo el espacio escolar como el lugar de transmisión de la cultura, así debe ser el escenario donde se construye la identidad personal. Acerca de esta visión escolar del Foro Latino, la escuela debe abrir espacios donde la persona desarrolla destrezas en diferentes artes, en consecuencia, la escuela debe centrar sus cambios no solo en el curriculum, sino en las formas de cómo se abordan los procesos de enseñanza y aprendizaje.

En la actualidad, a raíz de los cambios globales, se hace necesario promover el desarrollo de capacidades encaminadas a la aplicación de conocimientos de acuerdo a los adelantos sociales y tecnológicos, dentro del contexto educativo y que permitan generar nuevos conocimientos.

Los denominados pilares del aprendizaje del siglo XXI, definidos por la UNESCO, constituyen la mejor orientación para interrogarse acerca de los sentidos y contenidos de la educación: Aprender a ser, para conocerse y valorarse a sí mismo y construir la propia identidad para actuar con creciente capacidad de autonomía, de juicio y de responsabilidad personal en las distintas situaciones de la vida. Aprender a hacer, desarrollando competencias que capaciten a las personas para enfrentar un gran número de situaciones, trabajar en equipo y desenvolverse en diferentes contextos sociales y laborales. Aprender a conocer, para adquirir una cultura general y conocimientos específicos que estimulen la curiosidad para seguir aprendiendo y desarrollarse en la sociedad del conocimiento. Aprender a vivir juntos, desarrollando la comprensión y valoración del otro, la percepción de las formas de interdependencia, respetando los valores del pluralismo, la comprensión mutua y la paz. A ellos, hay que añadir "Aprender a emprender", 
para el desarrollo de una actitud proactiva e innovadora, haciendo propuestas y tomando iniciativas.

Al respecto PRELAC (2012, p. 47) Proyecto Regional de Educación para América Latina y el Caribe, destaca el problema de la repitencia escolar en su informe "reclamando que la repetición no logra que los alumnos mejoren los aprendizajes señalados, sino que por el contrario tiene efectos negativos en su autoestima y motivación, y supone un alto costo económico y social". Es por eso que los esfuerzos de directores y docentes deben dirigirse a generar cambios en las técnicas, estrategias y métodos, para que el aprendizaje del estudiante sea significativo y que dure para toda la vida.

\subsection{Calidad educativa}

El concepto de calidad educativa debe estar dirigido al beneficio de todos los alumnos en las escuelas, sin desviar la atención que permitan al docente mejorar los niveles de enseñanza y sobre todo el aprendizaje del estudiante; estos andamiajes del proceso educativo están incluidos por el Ministerio de Educación, desde la siguiente perspectiva:

Una educación será de calidad en la medida en que todos los elementos que intervienen en ella se orienten a la mejor consecución posible. El esfuerzo por mejorar la calidad de la educación tiene como últimos destinatarios a los alumnos. Son ellos quienes, finalmente, han de verse beneficiados por el mejor funcionamiento de los centros docentes. Lo que se intenta conseguir es que los alumnos de acuerdo con sus posibilidades, aprendan más y mejor, aprendan a aprender por sí mismos, desarrollen el gusto por el estudio, el deseo de saber más, y alcancen progresivamente una madurez personal, social y moral, que les permita actuar autónoma y responsablemente (MINEDUC, 1994).
De acuerdo con Palacios (1996) la calidad educativa es el proceso consensuado de construcción de objetivos para cada contexto y momento (...) como la trayectoria o tendencia que se realiza para conseguirlo. En esta dirección educativa, la calidad es visualizada como un proceso de construcción y/o fijación de objetivos educativos, no sólo referidos a los logros de los alumnos, sino a cuestiones curriculares y organizativas, a la vida del centro y el camino que recorren los actores del hecho educativo para lograrlos.

\subsection{El director escolar}

La función del director es determinante en el proceso educativo, el éxito o el fracaso de la institución dependen de la forma en que éste conduzca la labor que le corresponde, de la entrega que se manifieste en la resolución de problemas y la confianza que pueda generar con la comunidad educativa en general.

Para Mejía (2012) ser director de escuela, representa una oportunidad para promover la existencia, la calidad y el éxito de procesos pedagógicos que faciliten el cambio en la escuela; quiere decir que el rol directivo en una escuela implica el desarrollo de las competencias de los estudiantes a través de aprendizajes de calidad; por consiguiente, los estudiantes bajo ninguna circunstancia deben ser afectados por las condiciones desfavorables del contexto familiar y comunitario.

Por lo tanto, los docentes del centro educativo, siempre necesitan de un director que administre, distribuya responsabilidades, divida el trabajo, coordine esfuerzos y promueva el involucramiento del personal en la consecución de los objetivos que se pretenden en la institución educativa.

\subsection{El liderazgo}

Según el Diccionario de la Lengua Española (1986) y Diccionario de Ciencias de la Conducta (1956) es un intento de influencia in- 
terpersonal, dirigido a través del proceso de comunicación, al logro de una o varias metas y objetivos.

De acuerdo con Landolfi (2010) es el ejercicio manifestativo de las actualizaciones y perfeccionamientos de un ser humano, denominado líder, quien por su acción se coloca al servicio del logro, a través de una misión, de uno o varios objetivos propuestos por una visión. No obstante, en algunos centros educativos esta misión no es funcional, debido a la ausencia de estas herramientas que orientan la labor de los directores, tal y como lo describe el autor.

Para Richard L. Daft (2007) la relación de influencia que ocurre entre los líderes y seguidores, mediante la cual las dos partes pretenden llegar a cambios y resultados reales que reflejen los propósitos que comparten líderes y sus seguidores. En consecuencia, es oportuno elaborar en conjunto las directrices sobre las cuales se orientará el trabajo educativo entre los integrantes del cuerpo docente de los centros educativos.

Los directores escolares deben ser agentes que hagan operativo este conjunto de directrices para demostrar que el "Liderazgo Transformacional es el más idóneo para organizaciones educativas que aprenden", (Bolívar, A. 2010) puesto que favorece las metas comunes y compartidas, se potencia las capacidades y conocimientos que posee el personal, la consecución de las metas propuestas dentro de la institución se facilita, favoreciendo a la misma y al individuo en su desarrollo como profesional.

\subsection{El Liderazgo del Director Escolar}

La función de dirigir personas en instituciones educativas es considerada por algunos especialistas como una de las más complejas y difíciles tareas, puesto que exige de los empleados múltiples competencias. Orientada bajo esta perspectiva de transformación en competencias docentes, se busca transformar ese escenario de trabajo, donde las personas asumen responsabilidades que trascienden en el trabajo, produciendo un clima favorable de energía que fortalece todo lo que se hace en el centro educativo.

De acuerdo a la realidad guatemalteca, el sistema educativo, carece de un proceso adecuado de formación, selección y apoyo a los directores de escuelas del nivel primario, tomando en consideración que quienes ejercen tal función están nombrados como Director Profesor Titulado, como todos los docentes y desempeñándose al mismo tiempo como profesor con grado asignado. Por lo que se hace necesario que los mismos sean nombrados para la función que desempeñan y mejorar sus capacidades de liderazgo, para lograr mejoramiento continuo del aprendizaje de los estudiantes.

\subsection{Acompañamiento pedagógico}

De acuerdo con Galvis, A. y Leal, D. (2008) el acompañamiento pedagógico es un proceso intencionado y orientado hacia el mejoramiento de la calidad educativa, tiene como foco primordial el fortalecimiento de las competencias de los estudiantes y se lleva a cabo en los sitios de trabajo y no fuera de los mismos. Por lo tanto, este proceso es entendido como el vehículo que lleva hacia la consecución de la calidad de vida del individuo, además de exigir a los participantes un conocimiento compartido sobre la situación o problemática que se va a abordar y una organización rigurosa del tiempo en el que se va a llevar a cabo; busca lograr el cambio de los patrones de conducta y de actuación de las personas comprometidas en el proceso de enseñanza-aprendizaje.

El Ministerio de Educación de Guatemala, en seguimiento al cumplimiento de Convenios Internacionales, ha iniciado la implementación de un nuevo modelo de Supervisión Escolar a partir del 2010, como muestra piloto y ha sido denominado Sistema Nacional de Acompañamiento Educativo (SINAE). Este modelo 
de supervisión, destinado para los directores y docentes a nivel de aulas, parte de las necesidades de los establecimientos educativos, con vistas a fortalecer capacidades de gestión; acompañar un establecimiento educativo significa ponerse al lado de directivos y docentes, que guían el destino día a día, escuchando las necesidades e inquietudes, aportando miradas donde la escuela no puede ver y compartir con ellos herramientas que los ayuden en el que hacer pedagógico e institucional.

En estos esfuerzos que el Ministerio realiza y en alianza con Instituciones de apoyo, fue elaborada la Guía para el acompañante pedagógico, bajo la asesoría de Reforma Educativa en Aula del Proyecto auspiciado por USAID (2010). En esta guía aparecen directrices, cómo debe realizarse el acompañamiento a nivel de centro escolar y de aula, las competencias que debe poseer el acompañante. Pero, por sobre todo, conocimientos básicos que debe poseer el acompañante para el ejercicio de la labor en las aulas.

Bajo estas indicaciones y recomendaciones que los cooperantes dejan plasmadas en la guía de acompañamiento educativo, la labor del acompañante pedagógico no es simplemente visitar escuelas por cortesía y sin ningún propósito educativo; este modelo de supervisión va mucho más allá, tiene un propósito definido, el cual se concreta al hacer preguntas profundas al director y docente, aplicar herramientas de coaching o entrenamiento y ser un agente de cambio para el bien de la educación del país.

\subsection{Comunidades de Aprendizaje}

Para el proyecto de Reforma Educativa en el Aula, USAID (2011) las Comunidades de Aprendizaje promueven la equidad y pertinencia en los procesos educativos con participación de la comunidad en general. Es decir que "una comunidad de aprendizaje fomenta la contextualización de la educación a las realidades socioculturales de cada comunidad". (Galvis, A. y Leal, D. 2008).
Según Palacios, S. (1996) es entendible que la comunidad de aprendizaje (CDA) es un grupo de personas que trabaja en un propósito común; la comunidad de aprendizaje se conforma de profesionales y no profesionales. En este caso, del acompañamiento pedagógico, la comunidad de aprendizaje tiene como propósito común, mejorar el aprendizaje y el rendimiento de los estudiantes. En ese sentido y línea de acción, en las escuelas debe procederse a la organización de comunidades de aprendizaje, ya que es el medio que "crea las condiciones de crecer individualmente para aumentar el conocimiento y la capacidad continua". (Wenger, Etienne, 2002).

De acuerdo con García, D. (2001) la formación continua de los docentes para mejorar la práctica y el desarrollo profesional es un tema central de una Comunidad de Aprendizaje. Tomando en cuenta que el desarrollo continuo de los docentes es necesario, para que cuenten con las herramientas básicas para implementar la Reforma Educativa en el aula, centrada en la formación de nuevos ciudadanos.

\section{Perfil del Acompañante Pedagógico}

Preparación Académica: Título de Licenciatura - Maestría en Educación o campo relacionado y experiencia en educación.

Valores: Responsable en horarios, tareas y compromisos, fomento del respeto mutuo, íntegro, comprometido con la equidad.

Conocimiento del contexto: Dominio del idioma de la región, conocimiento de la región donde trabaja, conocimiento de responsabilidades del director y docentes del centro educativo.

Liderazgo: Confianza en sí mismo, visión personal de ayudar, compromiso con la excelencia, personalidad dinámica, comunicación oral clara, humildad, cumple con objetivos.

Destrezas profesionales: Visión profesional, ser agente de cambio en el liderazgo académico y la formación docente. 
Dominio de metodología efectiva: Conocimiento del CNB, Planeación y uso de lecciones del CNB, utilizar técnicas de observación apropiadas, conocimiento de procesos de evaluación curricular, modelaje de técnicas de enseñanza efectiva, uso efectivo de evaluación formativa, planeación lógica de lecciones diarias y a largo plazo.

Quiere decir, entonces, que el rol del acompañante es de suma importancia, dado que le corresponde desarrollar habilidades, para detectar necesidades según las prácticas pedagógicas de los docentes, así como la capacidad de analizar, reflexionar, resumir y sintetizar utilizando un lenguaje claro y sencillo.

\section{Herramientas del Acompañante Pedagógico}

1. Ciclo de Reflexión: Consiste en momentos cíclicos de modelaje sobre reflexión de las prácticas recurrentes aplicadas en los centros escolares, pueden ser positivas o negativas; este ciclo comprende tres pasos o etapas importantes y deben aplicarse individualmente con directores y docentes; y son los siguientes: Enseñar y evaluar, analizar evidencias, reflexionar y planear.

2. El COC: Significa conversar con el docente por un período no mayor a tres minutos, antes de observar la clase; es preparar las condiciones adecuadas, de modo que el docente sienta confianza y seguridad en lo que hace. En este momento el docente abre la posibilidad de que su clase pueda ser observada.

El siguiente paso es observar la clase del docente, haciendo énfasis en la planificación de la clase, metodología utilizada, técnicas aplicadas, herramientas de evaluación empleadas, organización del aula, del material visual, entre otros. Es recomendable que la observación no exceda de cinco minutos, tampoco debe tomarse nota dentro del salón de clase. Para este momento el acompañante prepara la hoja de registro de la observación para dejar evidencia de los aspectos observados, es el momento de recoger datos.

El tercer paso consiste en conversar después de la observación en el aula; el acompañante inicia por reconocer, exaltar, premiar y valorar los aspectos positivos observados, induce al docente a la reflexión de dichos aspectos, provocándole el análisis de las prácticas y posibilidades de mejorar o implementar otras prácticas. Es de suma importancia abrir el espacio para la siguiente visita, anotar acuerdos conjuntos y agradecer el tiempo dedicado para escuchar, analizar, reflexionar y evaluar. Es recomendable que el acompañado exprese lo que piensa; hay que saber escucharle y no centrar el diálogo en el acompañante.

3. Continuo del coaching: El primer paso consiste en guiar al docente, al identificar que éste necesita ayuda profunda, ahora bien, si el docente a quien se acompaña tiene dominio o un poco de conocimiento acerca de lo que el acompañante pedagógico quiere compartirle, será necesaria la colaboración únicamente; puede ser que el acompañado posea habilidades y destrezas que le facilitan el desenvolvimiento en lo que hace, entonces el acompañamiento debe dirigirse a la orientación espontánea y esporádica.

\section{Resultados del acompañamiento}

Los directores y docentes en 20 centros escolares muestran la disponibilidad, para promover liderazgo educativo en las escuelas que les toca dirigir.

El personal de 20 escuelas comparte el clima armónico y confianza, logrando la empatía y seguridad para la organización del centro. 
La comunicación afectiva y efectiva como medio para sensibilizar a los directores y docentes de 20 escuelas es causa de la buena administración y organización del personal y alumnos del centro escolar.

El Acompañamiento pedagógico aplicado a 12 docentes de primer grado ha demostrado que en las 20 escuelas se promueven las técnicas innovadoras para el proceso de enseñanza y aprendizaje en las aulas; en consecuencia, disminuyó el ausentismo y la deserción escolar y aumentó la promoción de alumnos.

La buena práctica del acompañamiento ha provocado la comunicación afectiva y efectiva que a la vez se traduce en buena administración y organización del aula en 20 centros educativos.

La organización de 4 comunidades de aprendizaje ha creado un clima agradable de confianza entre docentes y directores, influyendo fuertemente en el mejoramiento de la calidad educativa en las escuelas.

Dos Comunidades de aprendizaje organizadas en 6 escuelas del municipio de
Mataquescuintla, integrada por 6 directores y 6 docentes de primer grado de educación primaria.

Dos Comunidades de aprendizaje organizadas en 14 escuelas del municipio de Jalapa, integradas por 14 directores y docentes de primer grado de educación primaria.

La deficiente aplicación de las herramientas de evaluación en el aula ha permitido la incorporación de la evaluación formativa en el aula como estrategia para aplicar metodología activa y participativa.

La inadecuada organización de las aulas ha permitido aplicar el COC, sugerir, recomendar y alcanzar acuerdos para incorporar técnicas creativas, innovadoras para administrar adecuadamente las aulas.

Los indicadores de promoción del ciclo escolar 2013, demuestran el mejoramiento en la retención, promoción y disminución de la no promoción de estudiantes en cada centro educativo; dichos resultados se muestran en las tablas 5,6 y 7 . 


\section{Tabla 5}

Registro de Resultados Finales de Promoción, Ciclo Escolar 2013 de escuelas acompañadas por la Licda. Vilma Edith Téllez Lima

\begin{tabular}{|c|c|c|c|c|c|c|c|c|c|}
\hline \multirow[b]{2}{*}{$\begin{array}{l}\text { Código unidad } \\
\text { de informatica }\end{array}$} & \multirow[b]{2}{*}{$\begin{array}{c}\text { Nombre de la } \\
\text { escuela }\end{array}$} & \multirow[b]{2}{*}{$\begin{array}{l}\text { Nombre del } \\
\text { director }\end{array}$} & \multirow[b]{2}{*}{$\begin{array}{l}\text { Docen- } \\
\text { tes por } \\
\text { grado }\end{array}$} & \multirow{2}{*}{$\begin{array}{l}\text { Grado y } \\
\text { seccion } \\
\text { atendi- } \\
\text { da }\end{array}$} & \multicolumn{5}{|c|}{ CICLO ESCOLAR 2013} \\
\hline & & & & & $\begin{array}{l}\text { Total de } \\
\text { alumnos } \\
\text { inscritos }\end{array}$ & $\begin{array}{l}\text { Promo- } \\
\text { vidos }\end{array}$ & $\begin{array}{l}\text { No Pro- } \\
\text { movidos }\end{array}$ & $\begin{array}{l}\text { Retirados } \\
\text { Definiti- } \\
\text { vamente }\end{array}$ & $\begin{array}{c}\text { Retirados } \\
\text { por Tras- } \\
\text { lado }\end{array}$ \\
\hline $21-01-0028-43$ & $\begin{array}{l}\text { EORM Caserío } \\
\text { Las Quebradi- } \\
\text { tas Aldea Or- } \\
\text { choj, Jalapa }\end{array}$ & $\begin{array}{l}\text { Mynor Ro- } \\
\text { berto Salazar } \\
\text { Flores }\end{array}$ & $\begin{array}{c}1 \\
\text { Docente }\end{array}$ & $1^{\circ} \cdot A$ & 11 & 6 & 5 & 0 & 0 \\
\hline $21-01-0031-43$ & $\begin{array}{l}\text { EORM Caserío } \\
\text { El Lazareto, } \\
\text { Jalapa }\end{array}$ & $\begin{array}{l}\text { Angélica Or- } \\
\text { tega Aguirre }\end{array}$ & $\begin{array}{c}1 \\
\text { Docente }\end{array}$ & $1^{\circ} . \mathrm{A}$ & 53 & 33 & 17 & 3 & 0 \\
\hline $21-01-0056-43$ & $\begin{array}{l}\text { EORM Aldea } \\
\text { Río Blanco } \\
\text { Abajo, Jalapa }\end{array}$ & $\begin{array}{l}\text { Aura Marina } \\
\text { Morales } \\
\text { Arreaga }\end{array}$ & $\begin{array}{c}1 \\
\text { Directora }\end{array}$ & $1^{\circ} . \mathrm{A}$ & 7 & 4 & 0 & 3 & 0 \\
\hline $21-01-0061-43$ & $\begin{array}{l}\text { EORM Aldea } \\
\text { Los Tablones, } \\
\text { Jalapa }\end{array}$ & $\begin{array}{l}\text { Hernán Amil- } \\
\text { car Castañe- } \\
\text { da Vaides }\end{array}$ & $\begin{array}{c}1 \\
\text { Director }\end{array}$ & $1^{\circ} \cdot A$ & 7 & 7 & 0 & 0 & 0 \\
\hline $21-01-0079-43$ & $\begin{array}{l}\text { EORM Aldea } \\
\text { La Laguna, } \\
\text { Jalapa }\end{array}$ & $\begin{array}{l}\text { Etelvina } \\
\text { López Marro- } \\
\text { quín }\end{array}$ & $\begin{array}{c}1 \\
\text { Docente }\end{array}$ & $1^{\circ} . \mathrm{A}$ & 22 & 16 & 6 & 0 & 0 \\
\hline 21-01-0198-43 & $\begin{array}{l}\text { EORM Caserío } \\
\text { Los Yanes, Al- } \\
\text { dea Río Blanco } \\
\text { Arriba, Jalapa }\end{array}$ & $\begin{array}{l}\text { Gladis Mai- } \\
\text { den Palma } \\
\text { Folgar }\end{array}$ & $\begin{array}{c}1 \\
\text { Directora }\end{array}$ & $1^{\circ} \cdot A$ & 2 & 2 & 0 & 0 & 0 \\
\hline $21-01-1242-43$ & $\begin{array}{l}\text { EORM Aldea } \\
\text { Los Laureles, } \\
\text { Jalapa }\end{array}$ & $\begin{array}{l}\text { Brenda Ma- } \\
\text { ritza Ortega } \\
\text { Gómez }\end{array}$ & $\begin{array}{c}1 \\
\text { Docente }\end{array}$ & $1^{\circ} \cdot \mathrm{A}$ & 58 & 28 & 6 & 19 & 5 \\
\hline 21-07-0048-43 & $\begin{array}{l}\text { EORM Caserío } \\
\text { Sanuyaso, Ma- } \\
\text { taquescuintla, } \\
\text { Jalapa }\end{array}$ & $\begin{array}{l}\text { Alberto José } \\
\text { Monterroso } \\
\text { Abrego }\end{array}$ & $\begin{array}{c}1 \\
\text { Docente }\end{array}$ & $1^{\circ} . A$ & 21 & 12 & 7 & 2 & 0 \\
\hline 21-07-0052-43 & $\begin{array}{l}\text { EORM Caserío } \\
\text { El Pajalito, Ma- } \\
\text { taquescuintla, } \\
\text { Jalapa }\end{array}$ & $\begin{array}{l}\text { Gladys Eliza- } \\
\text { beth Gonzá- } \\
\text { lez Pérez }\end{array}$ & $\begin{array}{c}1 \\
\text { Docente }\end{array}$ & $1^{\circ} \cdot A$ & 23 & 16 & 3 & 4 & 0 \\
\hline $21-07-0053-43$ & $\begin{array}{l}\text { EORM Caserío } \\
\text { Buena Vista } \\
\text { San Granadi- } \\
\text { ta, Aldea San } \\
\text { Granada, Ma- } \\
\text { taquescuintla, } \\
\text { Jalapa }\end{array}$ & $\begin{array}{l}\text { Rolando de } \\
\text { Jesús Lemus } \\
\text { Pacheco }\end{array}$ & $\begin{array}{c}1 \\
\text { Director }\end{array}$ & $1^{\circ} \cdot A$ & 3 & 2 & 1 & 0 & 0 \\
\hline
\end{tabular}

Fuente: Estadística Final Primer Grado, Ministerio de Educación, año 2013 


\section{Tabla 6}

Registro de Resultados Finales de Promoción, Ciclo Escolar 2013 de escuelas acompañadas por el Lic. Jorge Adelino Pérez Ucelo

\begin{tabular}{|c|c|c|c|c|c|c|c|c|c|}
\hline \multirow[b]{2}{*}{$\begin{array}{l}\text { Código unidad } \\
\text { de informatica }\end{array}$} & \multirow[b]{2}{*}{$\begin{array}{c}\text { Nombre de la } \\
\text { escuela }\end{array}$} & \multirow[b]{2}{*}{$\begin{array}{l}\text { Nombre del } \\
\text { director }\end{array}$} & \multirow[b]{2}{*}{$\begin{array}{l}\text { Docentes } \\
\text { por } \\
\text { grado }\end{array}$} & \multirow[b]{2}{*}{$\begin{array}{l}\text { Grado y } \\
\text { sección } \\
\text { atendida }\end{array}$} & \multicolumn{5}{|c|}{ CICLO ESCOLAR 2013} \\
\hline & & & & & $\begin{array}{l}\text { Total de } \\
\text { alumnos } \\
\text { inscritos }\end{array}$ & $\begin{array}{l}\text { Promo- } \\
\text { vidos }\end{array}$ & $\begin{array}{l}\text { No Pro- } \\
\text { movidos }\end{array}$ & $\begin{array}{l}\text { Retirados } \\
\text { definitiva- } \\
\text { mente }\end{array}$ & $\begin{array}{l}\text { Retirados } \\
\text { por tras- } \\
\text { lado }\end{array}$ \\
\hline $21-07-0032-43$ & $\begin{array}{l}\text { EORM Caserío, } \\
\text { San Francisco, } \\
\text { Mataquescuintla }\end{array}$ & $\begin{array}{l}\text { Arnoldo } \\
\text { Enrique Mix } \\
\text { Loy }\end{array}$ & $\begin{array}{c}1 \\
\text { Docente }\end{array}$ & $1^{\circ} . A$ & 10 & 10 & 0 & 0 & 0 \\
\hline $21-07-0034-43$ & $\begin{array}{l}\text { EORM Caserío } \\
\text { El Porvenir, Ma- } \\
\text { taquescuintla }\end{array}$ & $\begin{array}{l}\text { Mario Leonel } \\
\text { Sandoval } \\
\text { Martínez }\end{array}$ & 1 Director & $1^{\circ} . \mathrm{A}$ & 4 & 3 & 1 & 0 & 0 \\
\hline $21-07-0051-43$ & $\begin{array}{l}\text { EORM Caserío } \\
\text { La Esperanza, } \\
\text { Mataquescuintla }\end{array}$ & $\begin{array}{l}\text { Oscar Noé } \\
\text { Domínguez } \\
\text { Hernández }\end{array}$ & 1 Director & $1^{\circ} . A$ & 19 & 8 & 9 & 2 & 0 \\
\hline $21-01-0057-43$ & $\begin{array}{l}\text { EORM Caserío } \\
\text { Laguneta, Ja- } \\
\text { lapa }\end{array}$ & $\begin{array}{l}\text { Leyda Roxa- } \\
\text { na González } \\
\text { Cisneros }\end{array}$ & $\begin{array}{c}3 \\
\text { Docentes }\end{array}$ & $\begin{array}{l}1^{\circ} \cdot \mathrm{A} \\
1^{\circ} \cdot \mathrm{B} \\
1^{\circ} \cdot \mathrm{C}\end{array}$ & 115 & 60 & 41 & 14 & 0 \\
\hline $21-01-0162-43$ & $\begin{array}{l}\text { EORM Caserío } \\
\text { Laguna del } \\
\text { Sapo, Jalapa }\end{array}$ & $\begin{array}{l}\text { Leslie Mabel } \\
\text { Vicente Rosil }\end{array}$ & $\begin{array}{c}1 \\
\text { Docente }\end{array}$ & $1^{\circ} \cdot \mathrm{A}$ & 43 & 27 & 16 & 0 & 0 \\
\hline $21-01-0164-43$ & $\begin{array}{l}\text { EORM Caserío } \\
\text { Laguna Seca, } \\
\text { Jalapa }\end{array}$ & $\begin{array}{l}\text { Marleen } \\
\text { Ericka Solór- } \\
\text { zano Cam- } \\
\text { pos }\end{array}$ & $\begin{array}{c}2 \\
\text { Docentes }\end{array}$ & $\begin{array}{l}1^{\circ} \cdot A \\
1^{\circ} \cdot B\end{array}$ & 63 & 39 & 21 & 3 & 0 \\
\hline $21-01-0175-43$ & $\begin{array}{l}\text { EORM Caserío } \\
\text { EI Pinalito, Ja- } \\
\text { lapa }\end{array}$ & $\begin{array}{l}\text { Marleny Eli- } \\
\text { cenia Mora- } \\
\text { les Zapata }\end{array}$ & $\begin{array}{c}1 \\
\text { Docente }\end{array}$ & $1^{\circ} . A$ & 42 & 20 & 21 & 1 & 0 \\
\hline 21-01-0199-43 & $\begin{array}{l}\text { EORM Caserío } \\
\text { El Quetzal, } \\
\text { Jalapa }\end{array}$ & $\begin{array}{l}\text { Ribelino } \\
\text { Francisco } \\
\text { Ucelo Jimé- } \\
\text { nez }\end{array}$ & $\begin{array}{c}1 \\
\text { Directora }\end{array}$ & $1^{\circ} . A$ & 42 & 27 & 14 & 1 & 0 \\
\hline $21-01-0202-43$ & $\begin{array}{l}\text { EORM Caserío } \\
\text { El Pino, Jalapa }\end{array}$ & $\begin{array}{l}\text { Marisela } \\
\text { Marroquín } \\
\text { Cisneros }\end{array}$ & $\begin{array}{c}1 \\
\text { Docente }\end{array}$ & $1^{\circ} . A$ & 37 & 18 & 16 & 3 & 0 \\
\hline 21-01-0204-43 & $\begin{array}{l}\text { EORM Caserío } \\
\text { Los Cruces, } \\
\text { Jalapa }\end{array}$ & $\begin{array}{l}\text { Ana Gladys } \\
\text { Cordero } \\
\text { Berdúo }\end{array}$ & $\begin{array}{c}1 \\
\text { Docente }\end{array}$ & $1^{\circ} . A$ & 23 & 15 & 8 & 0 & 0 \\
\hline
\end{tabular}

Fuente: Estadística Final Primer Grado, Ministerio de Educación, año 2013 


\section{Tabla 7}

Resultados finales en primer grado primaria en 20 escuelas ciclo escolar 2012-2013

\begin{tabular}{|cccccccccc}
\hline Año & Inscritos & Promovidos & $\%$ & No promovidos & $\%$ & $\begin{array}{c}\text { Retirados } \\
\text { definitivamente }\end{array}$ & $\%$ & $\begin{array}{c}\text { Retirados por } \\
\text { traslado }\end{array}$ & $\%$ \\
\hline 2012 & 618 & 346 & 56.00 & 209 & 33.81 & 53 & 8.57 & 10 & 1.61 \\
\hline 2013 & 605 & 353 & 58.34 & 192 & 31.73 & 55 & 9.09 & 5 & 0.82 \\
\hline
\end{tabular}

Fuente: Estadística Final Primer Grado, Ministerio de Educación, año 2012-2013

\section{Gráfica 1}

Resultados finales en primer grado de primaria, ciclo escolar 2012-2013

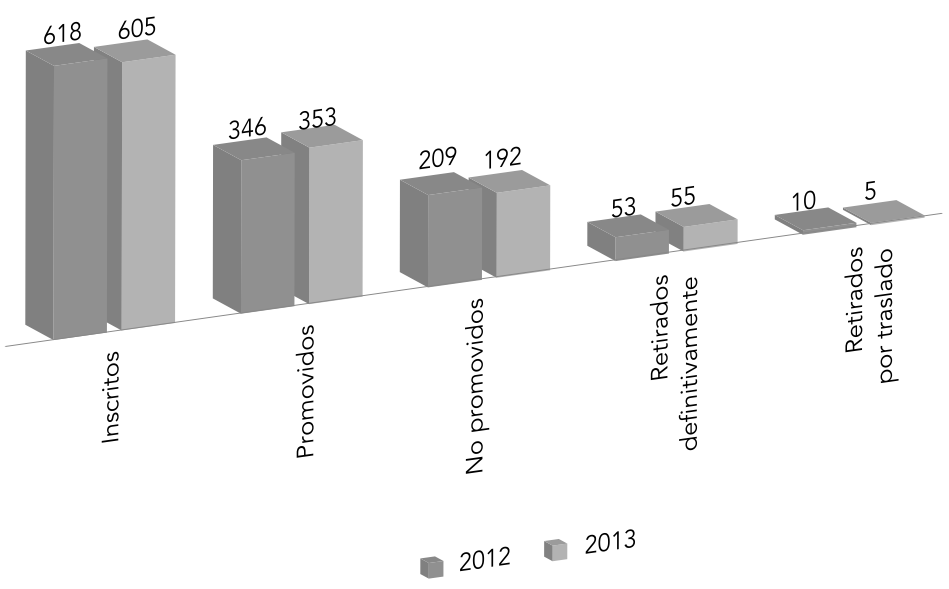

Fuente. Estadística Final, Ministerio de Educación, años 2012 y 2013.

\section{Lecciones aprendidas}

La buena utilización de las herramientas para el acompañamiento pedagógico (COC, Ciclo de Reflexión, Continuo de Coaching o entrenamiento) ha creado la disponibilidad de los directores y docentes para promover liderazgo educativo en las escuelas.

La oportuna aplicación del proceso de coaching o entrenamiento con los directores y docentes ha demostrado el mejoramiento del clima armónico y confianza en las escuelas logrando la empatía y seguridad de los docentes.

El Acompañamiento pedagógico a docentes de primer grado ha demostrado que en las escuelas se promueven técnicas innovadoras para el proceso de enseñanza y aprendizaje en las aulas.

La buena organización de las comunidades de aprendizaje ha creado un clima agradable de confianza entre docentes y directores.

La mala práctica de las herramientas de evaluación en el aula ha permitido la incorporación de la evaluación formativa en el aula como estrategia para aplicar metodología activa y participativa.

La inadecuada organización de las aulas ha permitido sugerir, recomendar y alcanzar acuerdos para incorporar técnicas creativas, innovadoras para administrar adecuadamente las aulas. 


\section{Conclusiones}

Las visitas de acompañamiento pedagógico a centros educativos permitieron fortalecer el liderazgo del Director del Centro Educativo, lográndose en ellos procesos de reflexión sobre las diferentes oportunidades de mejora para el centro educativo, mediante la organización de comisiones de trabajo con el personal, al planificar, elaborar y programar reuniones con el personal docente y padres de familia, participando en el desarrollo de procesos de capacitación y de elaboración del Proyecto Educativo Institucional de la escuela, promoviendo la práctica de valores, brindando acompañamiento a los docentes a nivel de aula.

El Acompañamiento Pedagógico a nivel de aula con los docentes de primer grado de escuelas asignadas permitió realizar procesos de reflexión y mejora de experiencias pedagógicas practicadas, mediante la aplicación de pasos del aprendizaje significativo, desarrollo de estrategias para la comprensión lectora, uso de libros de texto, comunicación y lenguaje y matemática, enriquecimiento de rincones de aprendizaje, uso de materiales concretos para el aprendizaje en la matemática y comunicación y lenguaje, organización y ubicación de niños en pequeños grupos de trabajo cooperativo, desarrollo de actividades lúdicas y aquellas que promueven la participación e interrelación entre los estudiantes.

Mediante el Acompañamiento a los centros educativos asignados, se logró capacitar y organizar a Directores y Docentes de Primer Grado Primaria en Comunidades de Aprendizaje, contándose para el efecto con cronogramas elaborados para la realización de reuniones durante el ciclo escolar 2013.

El Acompañamiento a nivel de Aula permitió a los docentes desarrollar actividades de evaluación formativa para consolidar el aprendizaje de los estudiantes, mediante procesos de observación, apoyo, retroalimentación, uso de hojas de trabajo y material concreto, ejercitación y práctica de actividades lúdicas.

\section{Recomendaciones}

Las Autoridades Educativas deben brindar el apoyo correspondiente, asignando recurso humano, material y financiero necesario, a fin de que el personal de la Supervisión Educativa, pueda desarrollar procesos de seguimiento a las escuelas en las que se tuvo a bien desarrollar el Acompañamiento Pedagógico.

Los Supervisores Educativos de los distritos correspondientes en los cuales se llevó a cabo el Acompañamiento, deben dar seguimiento al proceso de acompañamiento desarrollado, para el fortalecimiento del Liderazgo del Director y que éste a su vez pueda constituirse en un acompañante de los procesos de los docentes a cargo.

Los Directores de Centros Educativos Acompañados, deben poner en práctica las diferentes herramientas del Coaching o entrenamiento a nivel de aula con sus docentes para que junto con ellos se reflexione sobre las prácticas educativas que se desarrollan y lograr con ello la mejora continua.

Los docentes acompañados deben participar en procesos de formación continua que les permita desarrollar experiencias exitosas para lograr un aprendizaje significativo en sus estudiantes.

Los docentes y directores escolares deben participar activa y constantemente en las comunidades de aprendizaje organizadas en los municipios donde se realizó el acompañamiento educativo.

\section{Referencias}

Bolívar, A. (2010). "El liderazgo educativo y su papel en la mejora" una revisión actual de sus posibilidades y limitaciones. Psicoperspectivas, 9 (2), 9-33. Vol. 9, Universidad de Granada, España. 
CPRG (Constitución Política de la República de Guatemala) (1985). Asamblea Nacional Constituyente, Guatemala: Impresión Litográfica.

CRG (Congreso de la República de Guatemala) (1991). Decreto 12-91 Ley de Educación Nacional. Guatemala: Diario de Centro América.

Galvis, A. y Leal, D. (2008). Aprendiendo en comunidades: más allá de aprender y trabajar en compañía. Instituto Latinoamericano de Tecnología Educativa. México. D.F.

García, D. (2001). Reflexiones sobre pedagogía del seguimiento a la práctica educativa (documento interno de la SEE).

Landolfi, H. (2010), "Escuela de Filosofía Aplicada para la Excelencia del Ser Humano", Belgrano 919-1642 San Isidro-Buenos Aires-Argentina.

MINEDUC (Ministerio de Educación) (1994). Política social y deporte. Guatemala: Centro de Publicaciones.

MINEDUC (Ministerio de Educación) (2009). Las misiones de supervisión, monitoreo y acompañamiento pedagógico. Guatemala.

Nérici, I. (1985). Hacia una didáctica general dinámica. Buenos Aires, Argentina: Editorial Kapelusz.
Palacios, S. (1996). Instituciones educativas para la calidad total. Madrid: Editorial La Muralla.

PRELAC, (Proyecto Regional de Educación para América Latina y el Caribe) (EPT 2012). Informe Regional de Monitoreo del Progreso hacia una Educación de Calidad para Todos en América Latina y el Caribe.

Richard L. Daft. (2007). La experiencia del liderazgo. Ediciones Paraninfo. (Tercera Edición). Madrid, España.

USAID (Agencia de los Estados Unidos de América para el Desarrollo Internacional) (2010). Reforma Educativa en el Aula. Guía para el acompañante pedagógico. Guatemala.

USAID (Agencia de los Estados Unidos de América para el Desarrollo Internacional) (2011). Políticas educativas número 2. Guatemala.

Vigotsky, L. (2012). Teoría de las emociones. Estudio Histórico-Psicológico, Madrid, Akal Colección. Universidad de Córdova, Argentina.

Wenger, Etienne. (2002). Cultivating Communities of Practice: A Guide to Managing Knowledge. Boston, Massachusetts: Harvard Business School Press. 